\title{
Concentration-dependent Activation of Inflammatory/Anti-inflammatory Functions of Macrophages by Hydrolyzed Whey Protein
}

\author{
TORU TASAKA ${ }^{1}$, EMI KUWADA ${ }^{2}$, YUKA IZUCHI ${ }^{2}$, RYOHEI NISHIGAWA ${ }^{2}$, HISATSUGU YAMADA ${ }^{2}$, \\ HIDEKI UNUMA ${ }^{1}$, KEN TOKUNAGA ${ }^{1}$, AKIO HAYAKAWA ${ }^{1}$, AKITERU GO $^{1}$, KIKYO GO $^{3}$ and YOSHIHIRO UTO ${ }^{2}$ \\ ${ }^{1}$ Kohkan Pharmaceutical Institute Co., Ltd., Tokyo, Japan; \\ ${ }^{2}$ Graduate School of Technology, Industrial and Social Sciences, Tokushima University, Tokushima, Japan; \\ ${ }^{3}$ Dermatology Go Clinic, Tokyo, Japan
}

\begin{abstract}
Background/Aim: Whey protein is a mixture of globulins isolated from whey and mainly composed of $\beta$-lactoglobulin, $\alpha$-lactoalbumin, and lactoferrin. In this study, whey protein was hydrolyzed using various proteases, and the macrophage activation was evaluated. Materials and Methods: Hydrolyzed whey protein was prepared using various proteases to evaluate phagocytic activity and cytokine productivity. Results: The results of SDS-PAGE and gel permeation chromatography $(G P C)$ analysis indicated that the molecular weight of whey protein was reduced using various proteases. The hydrolyzed whey protein showed a concentration-dependent induction of macrophage phagocytic activity. In addition, the hydrolyzed whey protein significantly enhanced the production of the inflammatory cytokine, TNF- $\alpha$. Production of the anti-inflammatory cytokine, IL-10, was not observed at concentrations up to $1 \mu \mathrm{g}$, but significant production was confirmed at $100 \mu \mathrm{g}$. Conclusion: Hydrolyzed whey protein can induce the phagocytic activity of macrophages and activation of the inflammatory/anti-inflammatory functions of the macrophages depends on the concentration of the hydrolyzed whey protein.
\end{abstract}

Macrophages are cells that are responsible for innate immune responses and act to phagocytize foreign substances, such as

This article is freely accessible online.

Correspondence to: Dr. Yoshihiro Uto, Graduate School of Technology, Industrial and Social Sciences, Tokushima University, Tokushima University, 2-1 Minamijosanjima-cho, Tokushima, 7708506, Japan. Tel/Fax: +81886567514, e-mail: uto.yoshihiro@ tokushima-u.ac.jp

Key Words: Hydrolyzed whey protein, macrophage activation, inflammation, anti-inflammation, protease. bacteria, viruses, and cancer cells (1-3). We have previously succeeded in developing the macrophage activating agents "serum GcMAF", made from human serum (4), and "colostrum MAF", made from bovine colostrum (5). GcMAF (group-specific component $(\mathrm{Gc})$ protein-derived macrophage activating factor) is a glycoprotein with an $\mathrm{N}$ acetylgalactosamine (GalNAc) moiety, produced by deglycosylation of the Gc protein (a vitamin D binding protein) in the serum $(6,7)$. It has been reported that GcMAF enhances the phagocytic, antiangiogenic, and antitumor activities of macrophages (8-10). GcMAF has also been used in clinical research and for treating cancer and multiple sclerosis (11-13). Similar to GcMAF, colostrum MAF is produced by deglycosylation of bovine colostrum and induces macrophage activation (5). In clinical trials with colostrum MAF, a remarkable improvement has been confirmed in inflammatory diseases, such as a serious infection or chronic fatigue syndrome (14). However, many problems, such as complications in the manufacturing processes used in the food industry and the regulations on the use of raw materials, such as blood and bovine colostrum, are still associated with serum GcMAF and colostrum MAF.

Therefore, this study focused on whey protein as an alternative raw material. Whey protein is a mixture of globulins that have been isolated from whey, a by-product in cheese manufacture. It is mainly composed of $\beta$ lactoglobulin, $\alpha$-lactalbumin, and lactoferrin, contains abundant immunostimulatory proteins, and is inexpensive and available in large quantities $(15,16)$. In addition, it has been reported that the hydrolysis product of whey protein plays a role in ameliorating immune diseases $(17,18)$.

In this study, in order to avoid the problems associated with the aforementioned GcMAF and colostrum MAF, hydrolyzed whey proteins were prepared using various proteases and the phagocytic activation and cytokine production of macrophages was evaluated. 


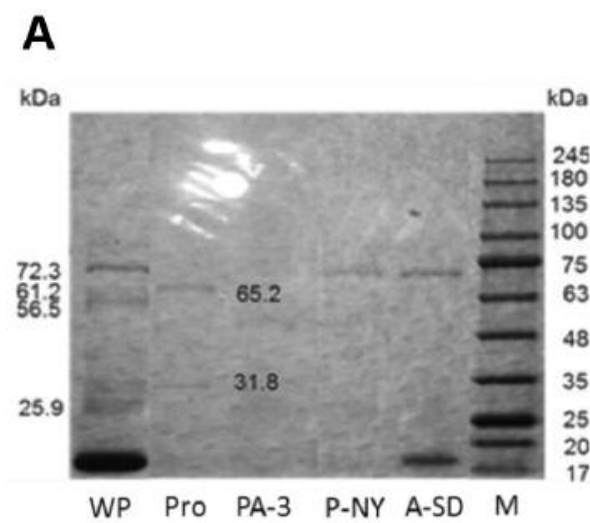

B

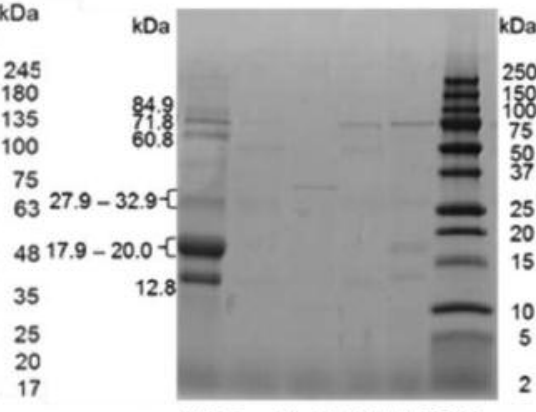

WP ProPA-3P-NYA-SDM
C

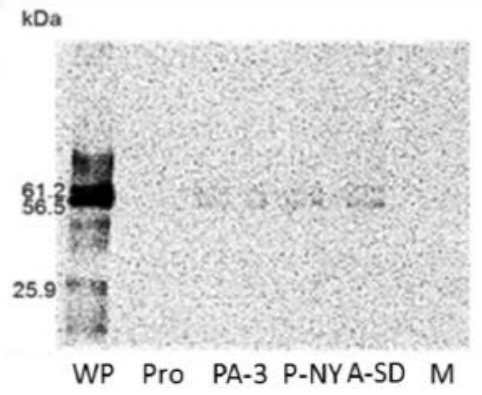

M

Figure 1. SDS-PAGE, CBB staining, and western blotting of protease-treated whey protein. (A) and (B) CBB-stained gels and (C) western blot probed with WFA lectin. M: Marker; WP: whey protein; Pro: Proteax; PA-3: P Amano 3SD; P-NY: Protin NY 10; A-SD: A Amano SD.

\section{Materials and Methods}

Preparation of hydrolyzed whey protein. Three grams of whey protein (ProDiet 80S; Ingredia, France) were dissolved in $100 \mathrm{ml}$ of $100 \mathrm{mM}$ sodium phosphate buffer (SPB) ( $\mathrm{pH}$ 7.0) and stirred for about $20 \mathrm{~min}$ to prepare a $3 \%$ whey protein solution. The mixture was centrifuged at $9,000 \times g$ at $4^{\circ} \mathrm{C}$ for $1 \mathrm{~h}$, and the supernatant was collected. The collected supernatant was dialyzed in SnakeSkin Dialysis Tubing 3.5K (Thermo Fisher Scientific K.K., Tokyo, Japan) overnight. The dialyzed solution was filtered through a $0.2 \mu \mathrm{m}$ filter (Advantec, Tokyo, Japan). Each protease $(1.35 \mathrm{mg})$, namely, $\mathrm{P}$ Amano 3SD, A Amano SD, Proteax, or Protin NY 10, (Amano Enzyme Inc., Nagoya, Japan) was added to the whey protein $\left(27 \mathrm{mg}\right.$ ) and allowed to react at $37^{\circ} \mathrm{C}$ for $1 \mathrm{~h}$ (P Amano 3SD) or $50^{\circ} \mathrm{C}$ for $1 \mathrm{~h}$, and the enzyme was inactivated by heat treatment at $60^{\circ} \mathrm{C}$ for $10 \mathrm{~min}$ (P Amano $3 \mathrm{SD}$ ) or at $80^{\circ} \mathrm{C}$ for $5 \mathrm{~min}$.

SDS-PAGE and western blotting. Hydrolyzed whey protein was subjected to sodium dodecyl-polyacrylamide gel electrophoresis (SDS-PAGE; XV PANTERA GEL MP, $7.5-15 \%$ or $15-25 \%$; DRC Co., Ltd., Tokyo, Japan), and subsequently, electroblotted onto a nitrocellulose membrane. Non-specific binding was blocked by overnight incubation at $4^{\circ} \mathrm{C}$ in Tris-buffered saline $(\mathrm{pH} 7.4)$ containing $0.1 \%$ Tween 20 and $1 \%$ BSA. The membranes were then probed with Wisteria floribunda lectin (WFA) Biotin Conjugate (Vector Laboratories Inc., Burlingame, CA, USA), specific for the GalNAc moiety. After washing of the membrane, the blots were incubated with enhanced chemiluminescence (ECL) streptavidinhorseradish peroxidase (HRP) conjugate (GE Healthcare Life Sciences, Uppsala, Sweden) The blots were visualized with a LumiCube chemiluminescence analyzer (Liponics, Tokyo, Japan).

Gel permeation chromatography (GPC) analysis. GPC analysis was performed using a Shimadzu-LC20AD system (Shimadzu Corporation, Kyoto, Japan), equipped with a SPD-M20A detector and CTO-20AC column oven. Chromatographic separation was achieved using a TSKgel G3000SWXL column $(300 \times 7.8 \mathrm{~mm}$ i.d.; $5 \mu \mathrm{m}$ ) (Tosoh Corporation, Tokyo, Japan). GPC assay was performed using an isocratic system with a flow rate of $1 \mathrm{ml} / \mathrm{min}$, a column temperature of $25^{\circ} \mathrm{C}$, and $50 \mathrm{mM}$ phosphate buffer ( $\mathrm{pH}$ 6.8 ) with $150 \mathrm{mM}$ sodium chloride as the mobile phase. Ultraviolet (UV) detection was performed at $260 \mathrm{~nm}$. The injection volume was $100 \mu \mathrm{l}$. The total run time was $20 \mathrm{~min}$ for each injection. Data were acquired and processed with LabSolution LC/GPC (Shimadzu Corporation, Kyoto, Japan).

In vitro phagocytosis assay. Mouse peritoneal adherent cells, including macrophages, were collected from 8-week-old female ICR mice (Japan SLC, Hamamatsu, Japan), as previously reported by Uto et al. (5), and cultured in 24-well plates at a density of $5 \times 10^{5}$ cells/well in serum-free roswell park memorial institute medium (RPMI) 1640 (Life Technologies, Carlsbad, CA, USA) for $1 \mathrm{~h}$. The cultured cells were then washed three times with serum-free RPMI 1640 to separate adherent macrophages from non-adherent cells, such as $\mathrm{T}$ and $\mathrm{B}$ cells. Mouse peritoneal macrophages were layered onto coverslips in a 24-well plate and cultured for $15 \mathrm{~h}$. After a 3-h treatment with hydrolyzed whey protein, the cultures were assayed for phagocytic activity. Sheep red blood cells (SRBCs; Nippon BioSupp. Center, Tokyo, Japan) were opsonized by rabbit hemolytic serum (anti-sheep red blood cells, Cosmo Bio Co., Tokyo, Japan). Opsonized SRBCs $(0.5 \%)$ in serum-free RPMI 1640 were overlaid onto each macrophage-coated coverslip and cultured for $1.5 \mathrm{~h}$. The non-internalized erythrocytes were lysed by immersing the coverslip in a hypotonic solution (1/5-diluted phosphate-buffered saline). The macrophages were fixed with methanol, air-dried, and stained with Giemsa stain. The number of phagocytosed erythrocytes per cell was observed under a microscope; in total, 250 macrophages were counted for each data point. Data were expressed as the phagocytosis index (PI), which was defined as the percentage of macrophages with ingested erythrocytes multiplied by the average number of erythrocytes ingested per macrophage.

Enzyme-linked immunosorbent assay (ELISA) assay for cytokine production. RAW 264.7 cells (RIKEN BRC, Ibaragi, Japan) were cultured in Dulbecco's modified eagle's medium (DMEM) for $18 \mathrm{~h}$ and then washed with $1 \times$ PBS. One milliliter of DMEM was added as the control; $1 \mu \mathrm{g}$ of lipopolysaccharide (LPS; Sigma-Aldrich Co., St. Louis, MO, USA) and $10 \mathrm{ng}$ of mouse IFN $-\gamma$ recombinant protein 

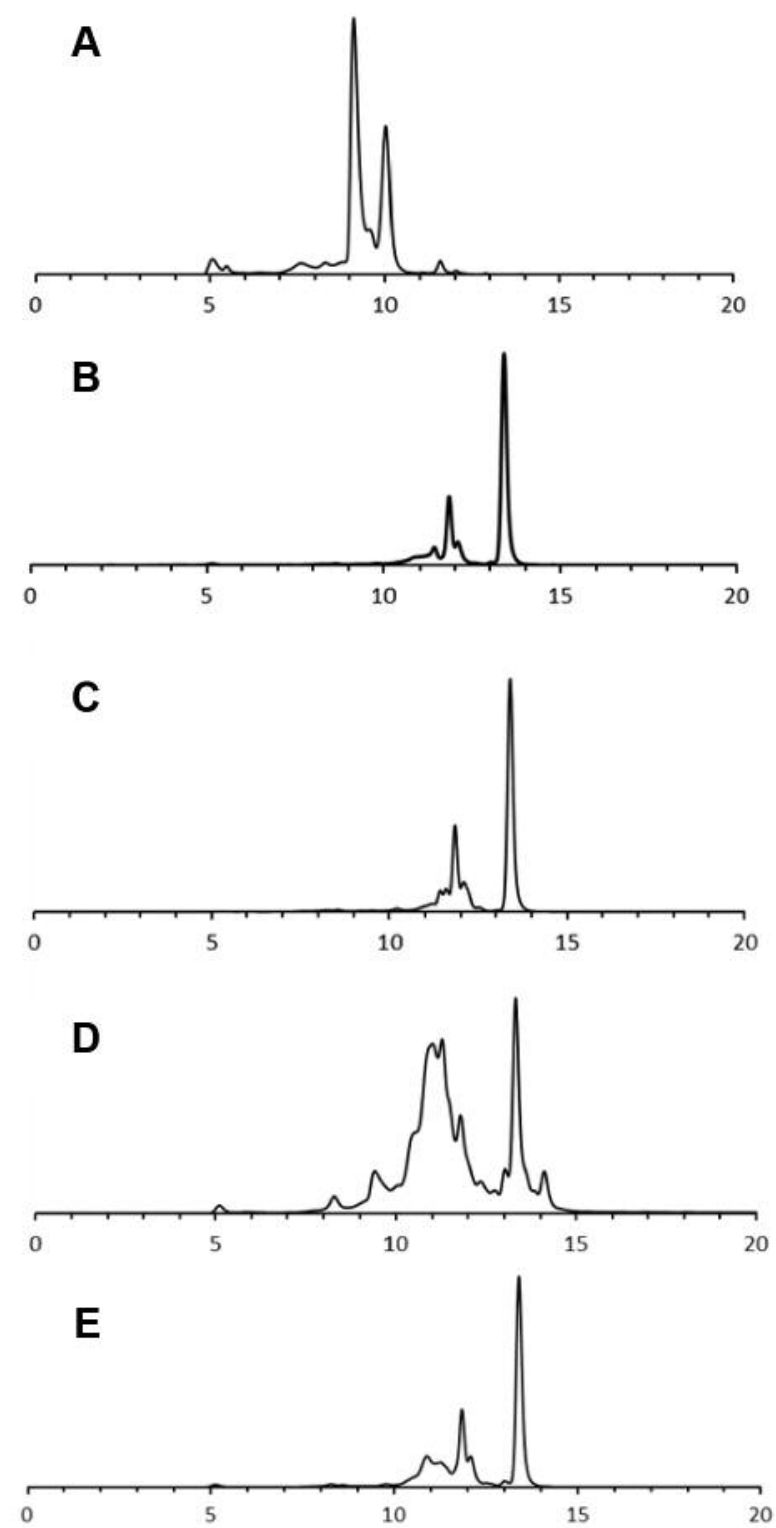

Figure 2. GPC of protease-treated whey protein. (A) Whey protein, $(B)$ Proteax, (C) P Amano 3SD, (D) Protin NY 10, and (E) A Amano SD.

(Thermo Fisher Scientific K.K.) was added as the positive control, or LPS $(10 \mu \mathrm{g})$ was used. Untreated whey protein or various protease-treated whey protein $100-1000 \mathrm{ng}(1-100 \mu \mathrm{g})$ was added to each sample and incubated at $37^{\circ} \mathrm{C}$ for $24 \mathrm{~h}$, and the culture supernatant was analyzed using a TNF- $\alpha$ mouse uncoated ELISA kit and an interleukin 10 (IL-10) mouse uncoated ELISA kit (Thermo Fisher Scientific K.K.), according to the instructions for use. To investigate the effect of the protease-treated whey protein on inflammation-induced macrophages, LPS $(1 \mu \mathrm{g})$ and IFN- $\gamma(10 \mathrm{ng})$ were added simultaneously with the protease-treated whey protein. Curcumin $(20 \mathrm{mM})$ served as the positive control.
Statistical analysis. Data are expressed as the mean with standard deviations of at least three independent experiments. The statistical significance of the differences between the results was analyzed using Student's $t$-test. $p<0.05$ was considered statistically significant.

\section{Results}

Preparation of hydrolyzed whey protein by protease treatment. We aimed to functionalize whey protein and tried to hydrolyze the whey protein using various proteases. The results of SDS-PAGE and coomassie brilliant blue (CBB) staining of the hydrolyzed whey protein showed that many bands (corresponding to molecular weights of 61.2, 56.5, 27.9-32.9, 25.9, 17.9-20.0, and $12.8 \mathrm{kDa}$ ), disappeared, as confirmed by the SDS-PAGE results of the untreated whey protein (Figure 1A and B). The intensity of the GalNAcpositive band greatly decreased for the untreated whey protein, as determined by western blotting using WFA lectin (Figure 1C). In addition, GPC analysis revealed that the main peak at 9-10 min, indicative of the untreated whey protein, disappeared, and new peaks were observed at 12 and 14 min, following treatment with the proteases (Figure 2A-E). These results suggest that we successfully prepared low molecular weight hydrolyzed whey protein using proteases.

Macrophage phagocytic activity of the hydrolyzed whey protein. In order to evaluate the immunomodulatory effect of the hydrolyzed whey protein, the activation of the phagocytic activity of mouse peritoneal macrophages was evaluated. All hydrolyzed whey proteins possessed the ability to activate the phagocytic activity of macrophages in a concentration-dependent manner (Figure 3A-D). In addition, 1-1000 ng hydrolyzed whey protein showed a significant enhancement of phagocytosis, compared to the untreated whey protein.

Cytokine production of hydrolyzed whey protein against macrophages. The ability of hydrolyzed whey protein to induce cytokine production in RAW 264.7 mouse macrophage cells was evaluated. Production of the inflammatory cytokine TNF- $\alpha$ increased significantly with $1000 \mathrm{ng}$ of hydrolyzed whey protein (Figure 4A). In contrast, in RAW 264.7 cells treated with LPS and IFN- $\gamma$, which is a proinflammatory factor, the hydrolyzed whey protein did not show a suppressive effect on TNF- $\alpha$ production (Figure 4B). Next, production of the antiinflammatory cytokine, IL-10, was not observed at concentrations up to $1 \mu \mathrm{g}$ of hydrolyzed whey protein, but when the amount was increased from $1 \mu \mathrm{g}$ to $100 \mu \mathrm{g}$, significant production of IL-10 was observed (Figure 4C).

\section{Discussion}

In this study, the effect of hydrolyzed whey protein on macrophage activation was investigated. From the results of 
A
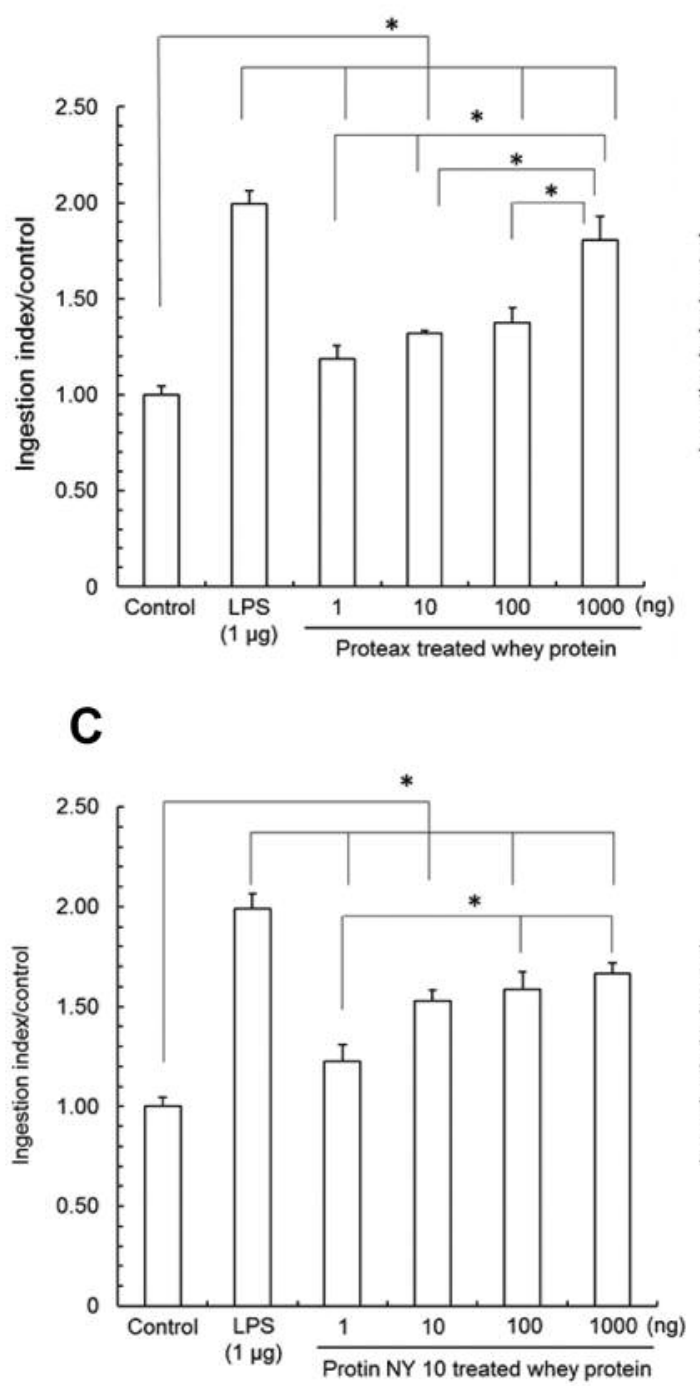

B
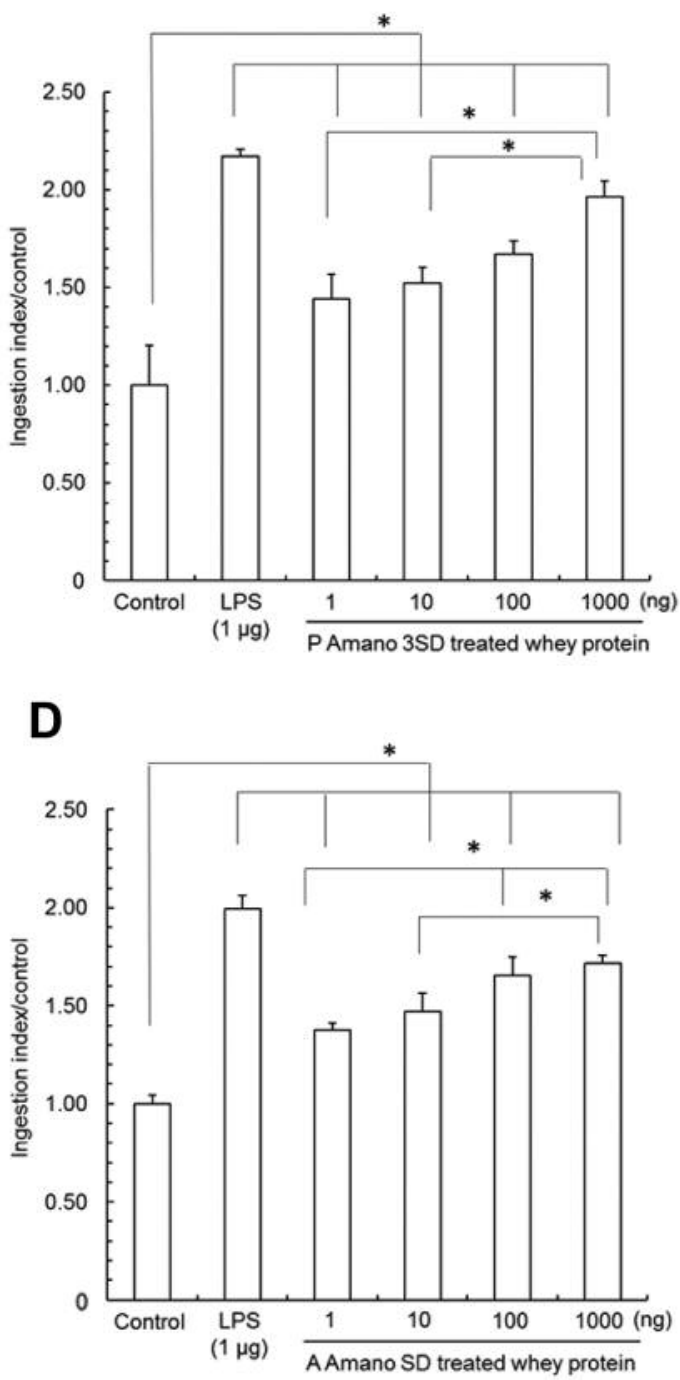

Figure 3. Macrophage phagocytic activity of hydrolyzed whey protein. (A) Proteax, (B) P Amano 3SD, (C) Protin NY 10, and (D) A Amano SD. Each experiment was performed three times. Data are the mean $\pm S D\left({ }^{*} p<0.05\right)$.

the SDS-PAGE and GPC analyses, it was shown that the whey protein, whose molecular weight was reduced following treatment with proteases, had a molecular weight of $5 \mathrm{kDa}$ or less. In addition, as the band intensity of Gc protein (at around $56 \mathrm{kDa}$ ), as determined by western blotting using WFA lectin, decreased considerably after protease treatment, it was inferred that the induction of macrophage phagocytic activity by the hydrolyzed whey protein is not due to the presence of GalNAc sugar moiety, such as the macrophage phagocytic activity induced by GcMAF (6). The hydrolyzed whey protein showed induction of TNF- $\alpha$ production and did not show a suppressive effect on TNF- $\alpha$ production by inflammation-induced macrophages, suggesting that hydrolyzed whey protein has the ability to induce differentiation of macrophages into inflammatory M1-type macrophages. Moreover, the expression of the CD86 antibody, a marker of M1-type macrophages was examined, and was found to be increased upon stimulation with hydrolyzed whey protein (data not shown). However, as a high concentration $(100 \mu \mathrm{g})$ of the hydrolyzed whey protein showed induction of the production of the anti-inflammatory cytokine, IL-10, peptides with anti-inflammatory properties were also suggested to be included in the hydrolyzed whey protein fraction. Therefore, identification of the active components and elucidation of the mode of action are extremely important. 
A



B

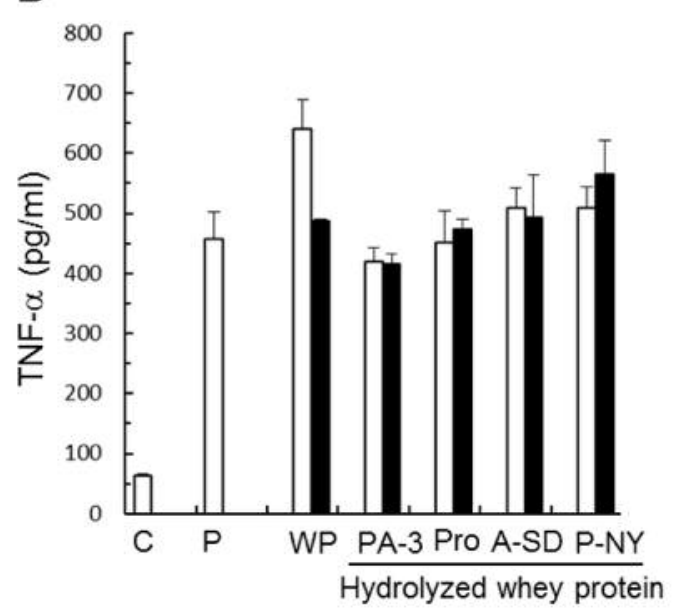

C

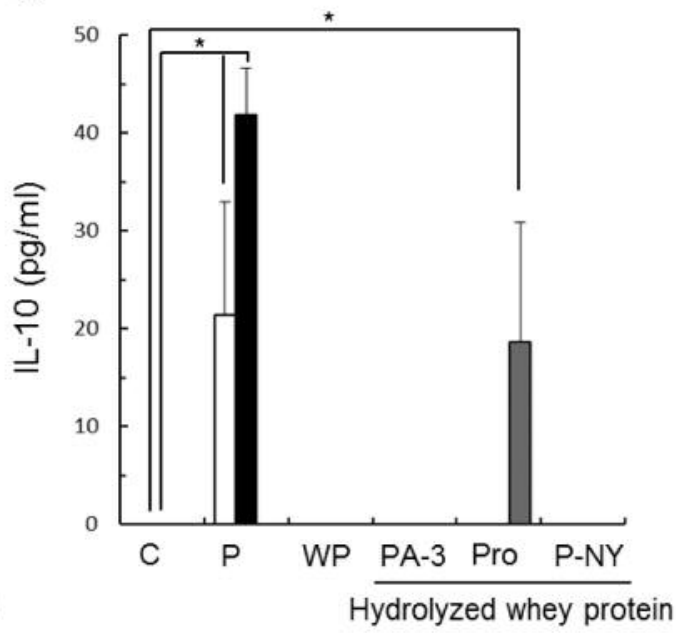

Figure 4. Cytokine production induced by hydrolyzed whey protein against macrophages. (A) TNF- $\alpha$ production, (B) TNF- $\alpha$ suppression, and (C) IL-10 production. WP: Whey protein; Pro: Proteax; PA-3: P Amano 3SD; P-NY: Protin NY 10; A-SD: A Amano SD. Open bar: 100 ng; closed bar: 1,000 ng; and gray bar: $100 \mu \mathrm{g}$. Each experiment was performed three times. Data are the mean $\pm S D(* p<0.05)$.

In conclusion, whey protein, whose molecular weight was reduced on treatment with proteases, induced macrophage phagocytic activity and inflammatory cytokine production at a low concentration and induced anti-inflammatory cytokine production at a high concentration. Therefore, hydrolyzed whey protein can regulate the balance of the immune function, in a concentration-dependent manner; therefore, its development as a supplement for treatment of cancer, infectious diseases, and autoimmune diseases is expected.

\section{References}

1 Cassetta L, Cassol E and Poli G: Macrophage polarization in health and disease. Sci World J 11: 2391-2402, 2011.

$2 \mathrm{Na}$ YR, Je S and Seok SH: Metabolic features of macrophages in inflammatory diseases and cancer. Cancer Lett 413: 46-58, 2018.
3 McClean CM and Tobin DM: Macrophage form, function, and phenotype in mycobacterial infection: lessons from tuberculosis and other diseases. Pathog Dis 74: ftw068, 2016.

4 Kuchiike D, Uto Y, Mukai H, Ishiyama N, Abe C, Tanaka D, Kawai T, Kubo K, Mette M, Inui T, Endo $\mathrm{Y}$ and Hori H: Degalactosylated/desialylated human serum containing GcMAF induces macrophage phagocytic activity and in vivo antitumor activity. Anticancer Res 33: 2881-2885, 2013.

5 Uto Y, Kawai T, Sasaki T, Hamada K, Yamada H, Kuchiike D, Kubo K, Inui T, Mette M, Tokunaga K, Hayakawa A, Go A and Oosaki T: Degalactosylated/desialylated bovine colostrum induces macrophage phagocytic activity independently of inflammatory cytokine production. Anticancer Res 35: 44874492, 2015.

6 Yamamoto N, Lindsay DD, Naraparaju VR, Ireland RA and Popoff SN: A defect in the inflammation-primed macrophageactivation cascade in osteopetrotic rats. J Immunol 152: 51005107, 1994. 
7 Nagasawa H, Uto Y, Sasaki H, Okamura N, Murakami A, Kubo $\mathrm{S}$, Kirk KL and Hori $\mathrm{H}$ : Gc protein (vitamin D-binding protein): Gc genotyping and GcMAF precursor activity. Anticancer Res 25: 3689-3695, 2005.

8 Koga Y, Naraparaju VR and Yamamoto N: Antitumor effect of vitamin D-binding protein-derived macrophage activating factor on Ehrlich ascites tumor-bearing mice. Proc Soc Exp Biol Med 220: 20-26, 1999.

9 Mohamad SB, Nagasawa H, Uto Y and Hori H: Preparation of Gc protein-derived macrophage activating factor (GcMAF) and its structural characterization and biological activities. Anticancer Res 22: 4297-4300, 2002.

10 Kisker O, Onizuka S, Becker CM, Fannon M, Flynn E, D'Amato R, Zetter B, Folkman J, Ray R, Swamy N and PirieShepherd S: Vitamin D binding protein-macrophage activating factor (DBP-maf) inhibits angiogenesis and tumor growth in mice. Neoplasia 5: 32-40, 2003.

11 Inui T, Kuchiike D, Kubo K, Mette M, Uto Y, Hori H and Sakamoto $\mathrm{N}$ : Clinical experience of integrative cancer immunotherapy with GcMAF. Anticancer Res 33: 2917-2919, 2013.

12 Inui T, Makita K, Miura H, Matsuda A, Kuchiike D, Kubo K, Mette M, Uto Y, Nishikata T, Hori H and Sakamoto N: Case report: a breast cancer patient treated with GcMAF, sonodynamic therapy and hormone therapy. Anticancer Res 34: 4589-4593, 2014.

13 Inui T, Katsuura G, Kubo K, Kuchiike D, Chenery L, Uto Y, Nishikata $\mathrm{T}$ and Mette M: Case report: GcMAF treatment in a patient with multiple sclerosis. Anticancer Res 36: 3771-3774, 2016.
14 Inui T, Kubo K, Kuchiike D, Uto Y, Nishikata T, Sakamoto N and Mette M: Oral colostrum macrophage-activating factor for serious infection and chronic fatigue syndrome: three case reports. Anticancer Res 35: 4545-4549, 2015.

15 Marshall K: Therapeutic applications of whey protein. Altern Med Rev 9: 136-156, 2004.

16 Badr G, Ramadan NK, Sayed LH, Badr BM, Omar HM and Selamoglu Z: Why whey? Camel whey protein as a new dietary approach to the management of free radicals and for the treatment of different health disorders. Iran J Basic Med Sci 20: 338-349, 2017.

17 Alexander DD, Schmitt DF, Tran NL, Barraj LM and Cushing CA: Partially hydrolyzed $100 \%$ whey protein infant formula and atopic dermatitis risk reduction: a systematic review of the literature. Nut Rev 68: 232-245, 2010.

18 Kankanamge R, Jeewanthi C, Lee NK and Paik HD: Improved functional characteristics of whey protein hydrolysates in food industry. Korean J Food Sci Anim Resour 35: 350-359, 2015.

Received April 11, 2018

Revised June 5, 2018

Accepted June 6, 2018 